\title{
Pharmaco-enzymes: The New Frontier in Enzymatic Activity Studies
}

\section{Bello Hassan Onimisi}

Department of Medicinal Chemistry and Pharmaceutical Chemistry, Olabaisi Onabanjo University, Sagam, Ogun State Nigeria

*Corresponding Author: Bello Hassan Onimisi, Department of Medicinal Chemistry and Pharmaceutical Chemistry, Olabaisi Onabanjo University, Sagam, Ogun State Nigeria.

Received: June 21, 2019; Published: July 10, 2019

DOI: $10.31080 /$ ASPS.2019.03.0331

The pharmacy scientist, chemist, biochemists and other elated scientist in other fields had tied over the years in contributing to enzymatic activity research. They have carried out works in different areas of enzymatic actions on drugs and xenobiotic, its action on the body and vice-versa.

In my search and research no work o initiative of science works had been put in place before now to look into enzymes acting as drugs and thereby acting synergistically with other drugs in action even when we limits its action as only been there to fast the rate of action.

In my laboratory here, our study (on-going) is showing that such claim of enzymes possessing pharmacological actions is not far from the truth. This why we name such enzymes as phamacoenzymes. In most of its action it sometimes unleash its pharmacological action only or enzymatic actions or both. We hope that at the end of our research our findings would prove all these and possibly classified them.

Furthermore, our study is also revealing that enzymes might have more than two site of actions of which one might compul- sorily be the site of pharmacological action. What is not clear yet is whether all enzymes have pharmacological actions or not. We would clarify this in not too distant a future.

Our is likely redefining enzymatic actions and its classifications.

\section{Volume 3 Issue 8 August 2019}

(c) All rights are reserved by Bello Hassan Onimisi. 